UDC 656

\title{
Validation of an Assistance System for Merging Maneuvers in Highways in Real Driving Conditions
}

\author{
S. Sanchez-Mateo ${ }^{1)}$, E. Perez-Moreno ${ }^{2)}$, F. Jimenez ${ }^{1)}$, F. Serradilla ${ }^{1)}$, A. Cruz Ruiz ${ }^{1}$, \\ S. de la Fuente Tamayo ${ }^{1)}$ \\ ${ }^{1)}$ Technical University of Madrid (Madrid, Kingdom of Spain), \\ ${ }^{2)}$ Complutense University of Madrid (Madrid, Kingdom of Spain) \\ (C) Белорусский национальный технический университет, 2019 \\ Belarusian National Technical University, 2019
}

\begin{abstract}
In the latest study conducted by the National Highway Traffic Safety Administration in 2018, it was published that human error is still considered the major factor in traffic accidents, $94 \%$, compared with other causes such as vehicles, environment and unknown critical reasons. Some driving scenarios are especially complex, such as highways merging lanes, where the driver obtains information from the environment while making decisions on how to proceed to perform the maneuver smoothly and safely. Ignorance of the intentions of the drivers around him leads to risky situations between them caused by misunderstandings or erroneous assumptions or perceptions. For this reason, Advanced Driver Assistance Systems could provide information to obtain safer maneuvers in these critical environments. In previous works, the behavior of the driver by means of a visual tracking system while merging in a highway was studied, observing a cognitive load in those instants due to the high attentional load that the maneuver requires. For this reason, a driver assistance system for merging situations is proposed. This system uses V2V communications technology and suggests to the driver how to modify his speed in order to perform the merging manoeuver in a safe way considering the available gap and the relative speeds between vehicles. The paper presents the results of the validation of this system for assisting in the merging maneuver. For this purpose, the interface previously designed and validated in terms of usability, has been integrated into an application for a mobile device, located inside the vehicle and tests has been carried out in real driving conditions.
\end{abstract}

Keywords: merging, human factor, assistance systems, driver behavior, cognitive load

For citation: Sanchez-Mateo S., Perez-Moreno E., Jimenez F., Serradilla F., Cruz Ruiz A., de la Fuente Tamayo S. (2019) Validation of an Assistance System for Merging Maneuvers in Highways in Real Driving Conditions. Science and Technique. 18 (6), 525-531. https://doi.org/10.21122/2227-1031-7448-2019-18-6-525-531

\section{Проверка эффективности вспомогательной системы для маневрирования в местах слияния автомобильных потоков в режиме реального вождения автомобиля}

\author{
С. Санчес-Матео ${ }^{1)}$, Э. Перес-Морено ${ }^{2)}$, Ф. Хименес ${ }^{1)}$, Ф. Серрадилла ${ }^{1)}$, \\ А. Крус Руис ${ }^{1)}$, С. де ла Фуэнте Тамайо ${ }^{1)}$ \\ ${ }^{1)}$ Мадридский политехнический университет (Мадрид, Королевство Испания), \\ ${ }^{2)}$ Мадридский университет Комплутенсе (Мадрид, Королевство Испания)
}

Реферат. В исследованиях, проведенных в 2018 г. Национальным управлением по безопасности движения автотранспорта, отмечено, что основной причиной дорожно-транспортных происшествий является человеческий фактор (94\% от всех других происшествий, которые вызваны такими причинами, как транспортное средство, окружающая среда и прочие критические ситуации). Некоторые сценарии вождения автомобиля носят особенно сложный и комплексный характер, например это переходно-скоростные полосы, когда водитель получает информацию для принятия решения о проведении плавного и безопасного маневра из окружающей среды. Незнание намерений водителей приводит к созданию рисковых ситуаций, которые вызваны отсутствием взаимопонимания или же ошибочными пред-

\section{Адрес для переписки}

Санчес-Матео София

Мадридский политехнический университет

Карретера де Валенсия (А-3), 7-й км,

28031, г. Мадрид, Королевство Испания

Тел.: 003469 958-90-57

Sofia.sanchez@upm.es

\author{
Address for correspondence \\ Sanchez-Mateo Sofia \\ Technical University of Madrid \\ km 7 Carretera de Valencia (A-3), \\ 28031, Madrid, Kingdom of Spain \\ Tel.: 003469 958-90-57 \\ Sofia.sanchez@upm.es
}


положениями и восприятием. Именно по этой причине рекомендуется использовать передовую вспомогательную систему вождения, которая предоставляет информацию для проведения безопасных маневров в критических ситуациях. В предыдущих работах поведение водителя в момент въезда в поток движущихся автомобилей на автостраде изучалось с помощью визуальной системы слежения, при этом наблюдалась когнитивная нагрузка вследствие огромной степени внимания, которого требует проведение того или иного маневра. Поэтому и предлагается применять вспомогательную систему вождения, которая наиболее эффективна в местах слияния автомобильных потоков, использует коммуникационные системы $\mathrm{V} 2 \mathrm{~V}$ и предоставляет информацию водителю о корректировке скорости с целью проведения безопасного маневра в местах слияния автомобильных потоков. При этом также анализируются расстояние между транспортными средствами и их скорости движения. Данная работа представляет результаты, подтверждающие эффективность применения этой системы в случае слияния автомобильных потоков. Ранее сконструированный и испытанный интерфейс интегрирован в мобильное устройство, которое прошло тестовые испытания в реальных условиях вождения и установлено внутри транспортного средства.

Ключевые слова: слияние, человеческий фактор, вспомогательные системы, поведение водителя, когнитивная нагрузка

Для цитирования: Проверка эффективности вспомогательные системы для маневрирования в местах слияния автомобильных потоков в режиме реального вождения автомобиля / С. Санчес-Матео [и др.] // Наука и техника. 2019. T. 18, № 6. C. 525-531. https://doi.org/10.21122/2227-1031-2019-18-6-525-531

\section{Introduction}

Reducing the number of traffic accidents is an issue that has been a social concern for quite some time. Today, thanks to the new technologies implemented in the automotive sector, it has been possible to alleviate the number of fatal accidents on the roads, but traffic accidents are still considered one of the leading causes of death worldwide according to recent studies by the World Health Organization [1].

According to the latest study carried out by the National Highway Traffic Safety Administration in 2018 [2], $94 \%$ of serious accidents are due to human errors related to the decision, such as performing illegal maneuvers, driving too fast, overconfidence or misjudgment of another car.

The increasing development of Advanced Driver Assistance Systems (ADAS) technologies helps to improve these situations because they assist the driver in making decisions in risky situations and suggest actions that favor not only the safety of the driver himself but also that of those around him.

However, some complex scenarios such as highway merging, which is the subject of this study, involve a high mental load for the user due to the large amount of information that must be processed while performing the merging maneuver. Timely decision making is crucial in this context since if it takes too long to enter the main road, the driver will reach the end of the acceleration lane without speed, assuming a risk of entering at a low speed on the highway.
That is why in previous studies [3, 4] a driver assistance system was proposed for the merging maneuver on highways. The following study is a continuation of the same one, in which the system design and its validation in real driving are presented.

\section{State-of-the-art}

ADAS offers great potential for further improving road safety, in particular by reducing driver error. Examples include adaptive cruise control (ACC), which permits maintaining a constant speed in accordance with road conditions and keeping a predetermined safety distance, pedestrian protection systems (PPS), capable of alerting the driver and acting autonomously to reduce the hit speed, and blind-spot detection (BSD), which indicates the existence of another vehicle or object in a blind spot in the rear detection area.

However, there are still many complex scenarios where human error is present due to the high amount of information that the driver has to process while making the right decision for the maneuver. Merging situation is one of the most critical scenarios that occur on the road because to perform a safe maneuver, the driver depends not only on the variables of his vehicle and the environment but also on the relative speed and position of adjacent vehicles.

Several authors have dedicated their studies to this situation, such as [5] which studied accidents in situations of lane change and merging, [6] which analyzed the time needed to perform a merging maneuver between young and elderly drivers 
or [7], which performed a realistic multi-driver merging simulation, where several driving simulators were connected to each other in order to have a more naturalistic behavior. This last study compares an ADAS cooperative system for merging situations in two conditions, single-driver simulation and multi-driver simulation, in which all drivers are warned of the maneuver that the ego vehicle is going to perform.

However, most of the studies carried out are in the field of simulation and very few in real driving, due to the cost and risk involved in performing tests, especially if there is dense traffic. In the study carried out by [8], real driving tests were carried out with 10 subjects, analyzing the effect of traffic density on the state of the driver's eye. From the results, he supported the need for a driving assistant that could suggest to the driver to accelerate or decelerate the vehicle depending on the gap necessary for merging. A study that serves as a precedent to ours is [9], which developed a merging system on highways, which provided a visual warning on a Google map on a smartphone, verified in real driving. Unlike ours, this article had three vehicles connected, indicating the need to accelerate, brake or enter the gap by means of three sentences according to the calculations of the algorithm until the end of the lane, in addition to being a more complex algorithm than ours.

This paper validates an application of merging assistance in real driving, based on cooperative systems, which have already been used in previous studies applied to the merging maneuver as for example [10] and [11]. Thanks to this technology the vehicles share internal variables of position and speed, proposing a more affable and safe environment.

\section{Assistance system design}

\section{Previous work}

In previous studies [3, 4] the influence of the merging situation on the cognitive behavior of the driver depending on traffic density was analyzed. The tests, carried out with several subjects in real driving using an eye-tracking system, confirmed that pupil diameter is a sensitive indicator of this type of situations. The fixations were also analyzed, whose duration was affected during the maneuver due to the amount of information to be processed in a single glance to the rear-view mir- ror. The frequency of mirror looks was also increased by $30 \%$ with respect to the baseline in normal driving. In [12] the fixations were also analyzed by means of heat maps, noting that there was a common hot zone in both rear-view mirrors when the merging maneuver was performed in most driving tests. This area, located in the upper-inner part of the rearview mirror, is considered adequate for the placement of the assistance system to be developed later.

\section{System development}

The proposed assistance system uses cooperative systems (C-ITS) based on Vehicle-to-vehicle $(\mathrm{V} 2 \mathrm{~V})$ communication, where vehicles share information on speed and position. This technology used in several experiments such as $[13,14]$ makes the environment safer and less hostile to adjacent vehicles, thanks to knowing the internal variables of the vehicles.

The variables of speed and position are the inputs of the mobile application that supports the assistance system. For the system interface, a simple bar design has been chosen (Fig. 1), based on previous ADAS development studies [15], where an intelligent speed adaption system was developed. The bars show in qualitative terms, how much to brake or accelerate once the vehicle starts to merge to the main road, guiding it to acquire an optimal speed.

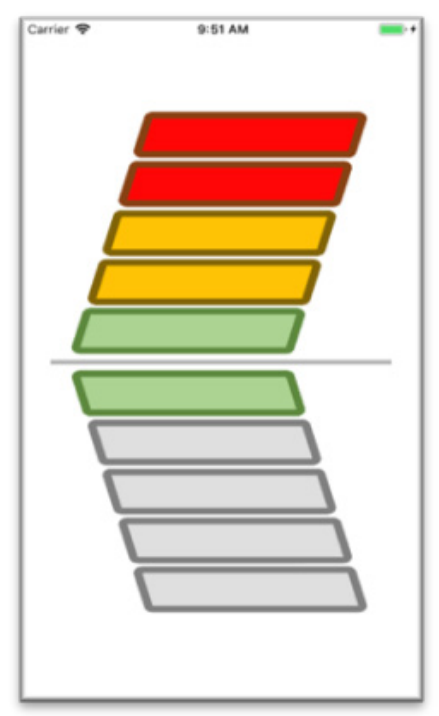

Fig. 1. Bar interface design

The main premises in the algorithm are:

1) the safety margin between vehicles must not be less than two seconds; 
2) the maximum speed of the road in the acceleration lane must not be exceeded in any case;

3 ) the assumed acceleration and deceleration limits to reach are 2 and $4 \mathrm{~m} / \mathrm{s}^{2}$ respectively $[16,17]$.

The reason for defining a safety margin in terms of time is because more speed requires more distance to brake. Numerous studies report that a driver reacts, in the worst case, with a reaction time of $1.5 \mathrm{~s}$ to a surprise event, as an object that moves suddenly on the driver's route [18]. This is why in a conservative way two seconds of time is chosen as the safety margin, so this variable can be applied to any scenario due to its dependence on speed and space.

On the algorithm are shown two main conditionals, the vehicle merge in front of the vehicle that is already in the main road, if safety conditions permit, or the vehicle merge behind the vehicle of the main road, either because it exceeds the maximum speed of the road or because the acceleration need is excessive.

The algorithm used, which is based on motion equations, is more intuitive and simple than the one presented in [19], where a decentralized algorithm for highway merging system was developed, which only indicated the need to accelerate, brake or enter.

The code written generically with the variables is attached below, as well as a flowchart (Fig. 2) to improve understanding:

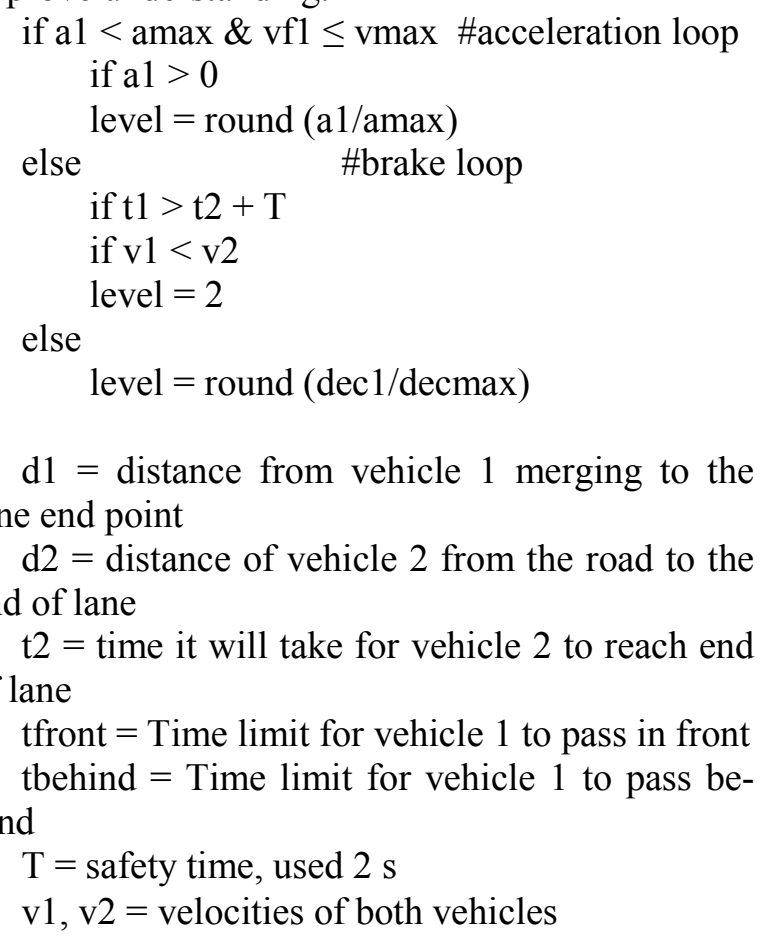

level $=$ amount of acceleration or braking vmax $=$ Maximum track speed in $\mathrm{m} / \mathrm{s}$ amax $=$ Maximum acceleration, using $2 \mathrm{~m} / \mathrm{s}^{2}$ decmax $=$ Maximum deceleration, using $4 \mathrm{~m} / \mathrm{s}^{2}$ a1 $=$ Instantaneous acceleration of 1 $\operatorname{dec} 1=$ Instantaneous deceleration of 1 .

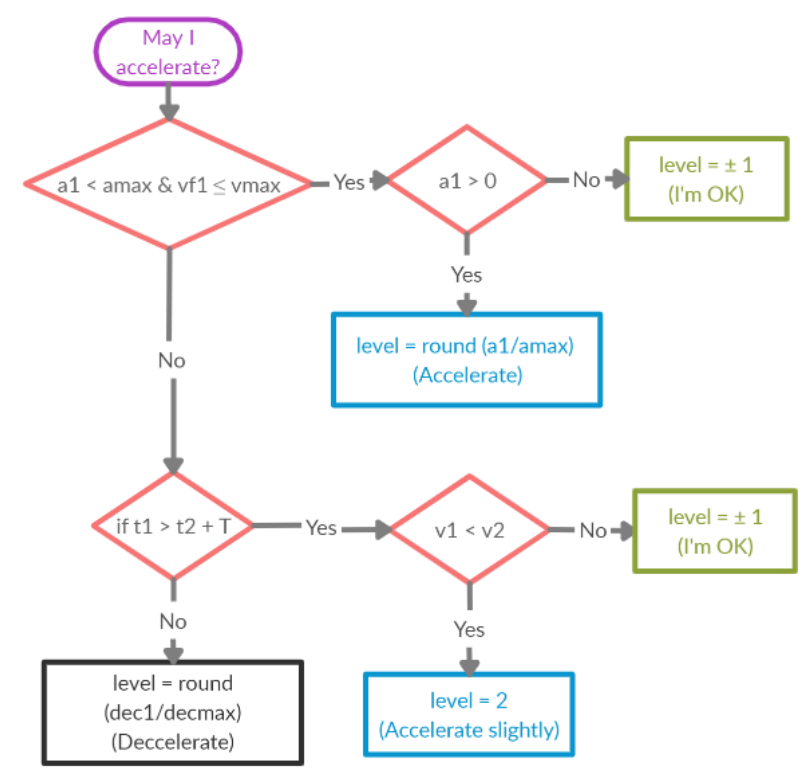

Fig. 2. System operation schematic

\section{System validation in real driving}

Three merging maneuvers were carried out along the M-45 highway in Madrid, Spain. Two On-Board Unit (OBU) G5 communication modules embedded in each of the vehicles, send information to the application through the wireless network, which generates only visual warnings based on the speed information and the positioning collected by the Global Navigation Satellite System (GNSS) on a digital map (Fig. 3).

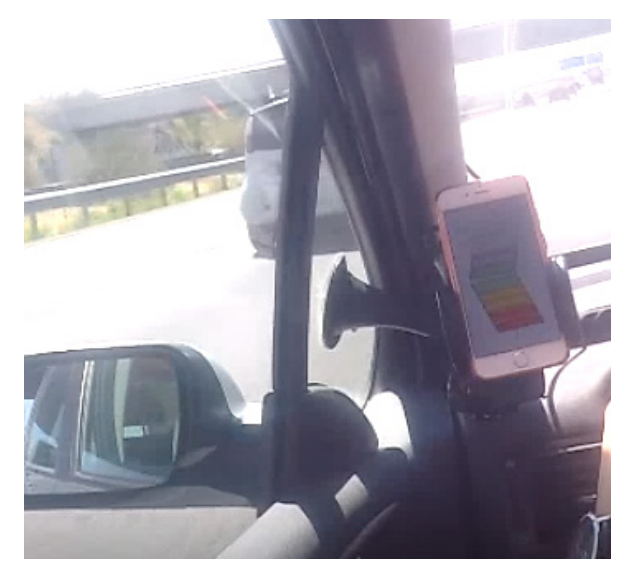

Fig. 3. Interface of merging assistance system 
The GNSS is an integrated satellite navigation receiver GLONASS + GPS + GALILEO + SBAS, whose sampling frequency for the position and speed values of each vehicle is $200 \mathrm{~m} / \mathrm{s}$ and which are the inputs to the control algorithm of the merging assistance interface (Fig. 4).

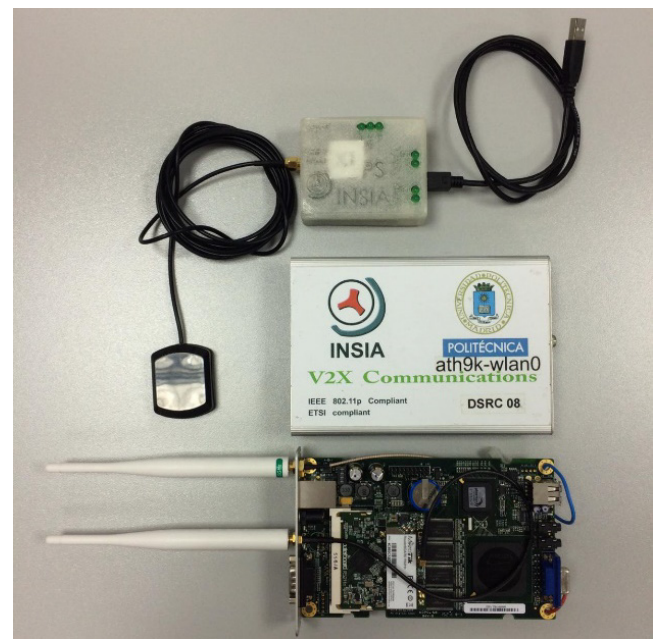

Fig. 4. Communications module and GNSS

The communication modules are connected to two external antennas each one located on the roof of the vehicle, 2.4 and $5.0 \mathrm{GHz}$ bandwidth (Fig. 5). The GNSS receiver are also fixed to the vehicle roof in order to obtain the best signal possible.

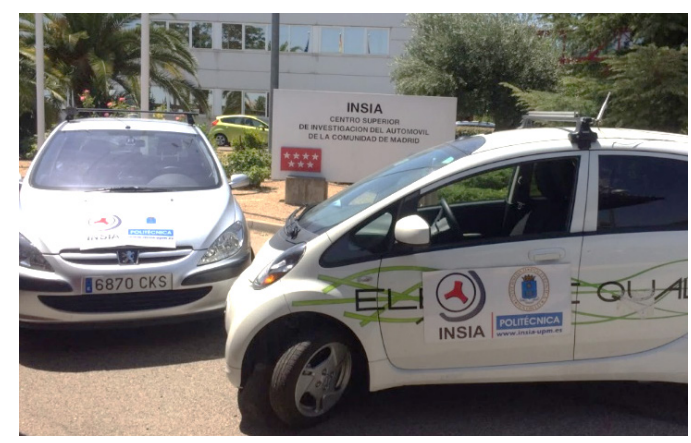

Fig. 5. Vehicles equipped with communications modules and GNSS

The driver will perform the three merging maneuvers supported by the visual warnings provided by the assistance system. The cognitive load of the task is studied examining the pupil diameter and the fixations by means of an ocular tracking system.

\section{Results}

Considering the environmental difficulties involved in performing a real driving test, the results obtained in the merging maneuvers have been satisfactory. The position, velocity and acceleration values for each maneuver were analyzed, as well as the levels shown in the application. A total of 13 subjects between the ages of 25 and 45, instrumented with an eye-tracking, performed the circuit. The fixations can be seen in a heat map below, performing a merging maneuver (Fig. 6).

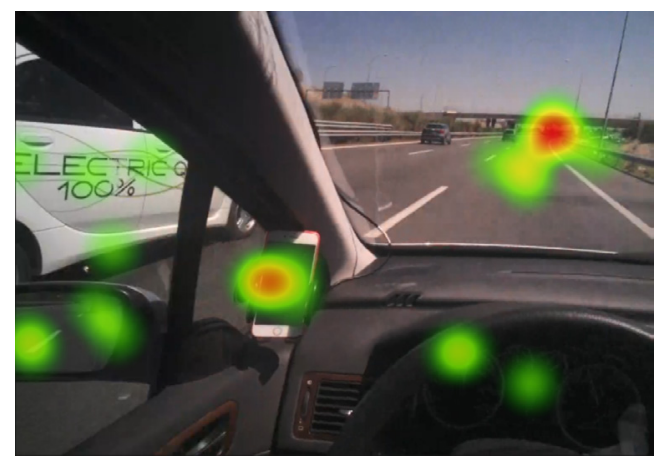

Fig. 6. Heat map of the merging maneuver

As you can see, the driver looks mainly at the road and the merging assistance application, as well as the vehicle and control panels. Also shown in the following graph as an example, are the internal data with which the application works and the levels of warning it generates, the positive level is the need to accelerate and the negative, the need to brake.

In the graphs, it can see to the left the velocities of each vehicle and to the right the distances to the lane end. The level is a dimensionless measure that indicates in the positive part the need to accelerate and in the negative part, the need to brake. As can be seen in Fig. 7, vehicle 1 is warned of the need to accelerate because, although it is closer to the lane end than vehicle 2, at first it starts with a speed of less than 2, and they will probably end up at the lane end. In this case vehicle 1 passes in front of vehicle 2 in the merging. In Fig. 8, the merging maneuver is very similar to the maneuver in Fig. 7, observing how the application warns of the need to accelerate at first, as it gives time to pass in front of vehicle 2. There is a negative peak downward in a particular instant because the speeds of the vehicles are equalized and vehicle 1 must accelerate if he wants to maintain its position with respect to vehicle 2. In Fig. 9, it can see the warnings at first but due to acceleration by vehicle 2, the application suggests passing behind the vehicle. 


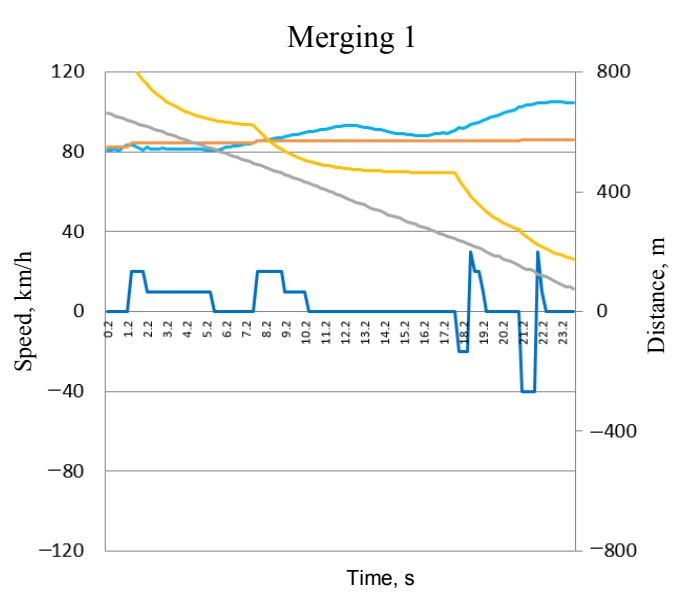

Fig. 7. Data in merging maneuver 1 :

-- level; $--\mathrm{v} 1 ;--\mathrm{v} 2 ;--\mathrm{d} 1 ;-\mathrm{d} 2$

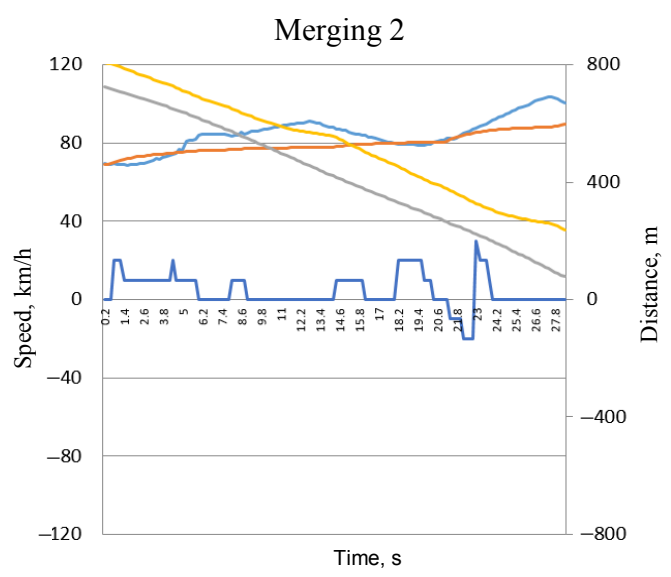

Fig. 8. Data in merging maneuver 2:

- level; —- v1; - - v2; - - d1; - - d2

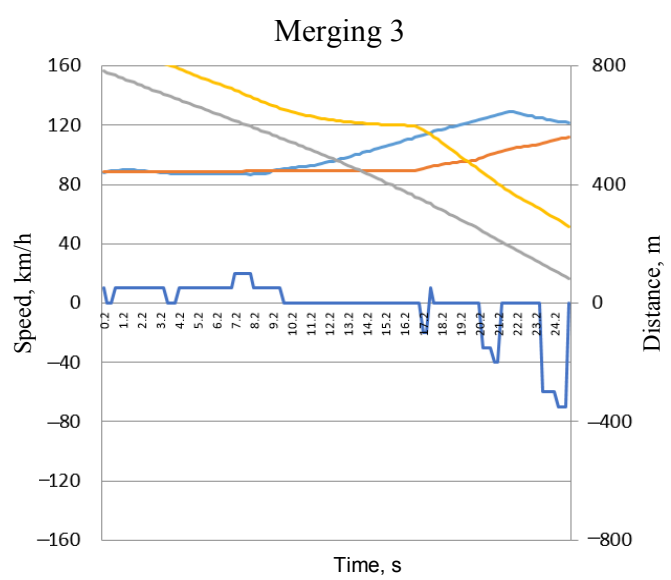

Fig. 9. Data in merging maneuver 3:

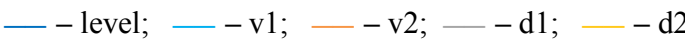

In the Tab. 1 times and distances have been summarized, in which the application gives negative warnings, that is to say to brake and the- refore pass behind the vehicle that is within the main road.

Table 1

Times and distances from the first negative warning to the lane end

\begin{tabular}{|l|c|c|c|}
\hline & Merging 1 & Merging 2 & Merging 3 \\
\hline Distance, $\mathrm{m}$ & 252.25 & 258.72 & 347.82 \\
\hline Time, $\mathrm{s}$ & 9.2 & 10.4 & 10.6 \\
\hline Level & -20 & -20 & -20 \\
\hline
\end{tabular}

These values are considered important, because if the driver does not react quickly and there is a situation of not having enough time to proceed to brake safely.

As can be seen from the results, there are no sharp level peaks, but the application suggests starting to brake gradually from level 20 . Time and distance are values of similar range in all incorporations, which indicates that it would not show warnings to accelerate when the driver is in a critical situation near the lane end.

\section{CONCLUSION}

In this paper, a merging assistance system based on $\mathrm{V} 2 \mathrm{~V}$ communications has been developed with the aim of making the maneuver safer for the driver. In view of the results obtained, it can be concluded that the application has had a good performance in the real driving tests. In the heat maps, it has been observed that the system is the second point that has more fixations when the maneuver is carried out, behind the fixations to the own lane. This result is very coherent, given that for the driver the final point of the lane is the most important, and he has to arrive at this point with sufficient foresight to be able to merge. On the other hand, seeing the data shown in the graph above and the operation of the application, the merging assistance system is validated in real driving conditions. It has been proven that the system in no case would suggest the driver accelerate near the lane end, which makes it considered a conservative and reliable system in terms of safety.

\section{ACKNOWLEDGEMENT}

This research has been partially funded by the Spanish Ministerio de Economia y Competitividad (CAV projectTRA2016-78886-C3-3-R), the Spanish Direccion General de Trafico - DGT (SICOTRAM project SPIP2017-02324), 
the Connected Europe Facility (CEF) Program under grant agreement No 2015-EU-TM-0243-S (AUTOCITS project) and No 2016-EU-TM-0272-S (C-ROADS Spain project). We cordially thank all our colleagues from the AUTOCITS and C-ROADS Spain projects for their collaboration in the C-ITS corridor deployment. We also thank all the participants in simulator and road tests.

\section{REFERENCES}

1. World Health Organization (2018) Global Status Report on Road Safety 2018. https://www.who.int/violence_ injury_prevention/road_safety_status/2018/en/.

2. National Highway Traffic Safety Administration. U.S. Department of Transportation (2018) Critical Reasons for Crashes Investigated in the National Motor Vehicle Crash Causation Survey. Report DOT HS 812 506. https://crash stats. nhtsa.dot.gov/api/public/viewpublication/812115.

3. Sanchez-Mateo S, Clavijo M., Díaz-Álvarez A., Jimenez F. (2018) Interface Design for an Assistance System Focused on High Attentional Load Situations. 25 $5^{\text {th }}$ ITS World Congress, Copenhagen, Denmark. Paper EU-TP1639.

4. Sanchez-Mateo S., Perez-Moreno E., Jiménez F., Naranjo J.E., Perez Flores C., Antoñazas Teruel J. (2018) Study of a Driver Assistance Interface for Merging Situations on Highways. 2018 IEEE International Conference on Vehicular Electronics and Safety (ICVES), Madrid, Spain. https://doi.org/10.1109/icves.2018.8519495.

5. Jula H., Kosmatopoulos E. B., Ioannou P. A. (2000) Collision Avoidance Analysis for Lane Changing and Merging. IEEE Transactions on Vehicular Technology, 49 (6), 2295-2308. https://doi.org/10.1109/25.901899.

6. de Waard D., Dijksterhuis C., Brookhuis K. A. (2009) Merging Into Heavy Motorway Traffic by Young And Elderly Drivers. Accident Analysis \& Prevention, 41 (3), 588-597. https://doi.org/10.1016/j.aap.2009.02.011.

7. Maag C., Muhlbacher D., Mark C., Kruger H.-P. (2012) Studying Effects of Advanced Driver Assistance Systems (ADAS) on Individual and Group Level Using MultiDriver Simulation. IEEE Intelligent Vehicles Symposium (IV), 4 (3), 45-54. https://doi.org/10.1109/ivs.2011. 5940419

8. Cheng Y., Gao L., Zhao Y., Du F. (2016) Drivers' Visual Characteristics when Merging Onto or Exiting an Urban Expressway. PLoS ONE, 11 (9), e0162298. https://doi.org/ 10.1371/journal.pone.0162298.

9. Salman Ahmed M., Hoque M. A., Rios-Torres J., Khattak A. J. (2018) A Cooperative Freeway Merge Assistance System Using Connected Vehicles. https://arxiv.org/abs/ 1805.00508 .
10. Rios-Torres J., Malikopoulos A. A. (2017) Automated and Cooperative Vehicle Merging at Highway On-Ramps. IEEE Transactions on Intelligent Transportation Systems, 18 (4), 780-789. https://doi.org/10.1109/tits.2016.2587582

11. Milanes V., Godoy J., Villagra J., Perez J. (2011) Automated On-Ramp Merging System for Congested Traffic Situations. IEEE Transactions on Intelligent Transportation Systems, 12 (2), 500-508. https://doi.org/10.1109/tits. 2010.2096812.

12. Jiménez F., Naranjo J. E., Sanchez-Mateo S., Serradilla F., Pérez E., Hernández M. J., Ruiz T. (2018) Communications and Driver Monitoring Aids for Fostering SAE Level-4 Road Vehicles Automation. Electronics, 7 (10), 228. https://doi.org/10.3390/electronics7100228.

13. Sakr A. H., Bansal G., Vladimerou V., Kusano K., Johnson M. (2017) V2V and Onboard Sensor Fusion for Road Geometry Estimation. 2017 IEEE 20 ${ }^{\text {th }}$ International Conference on Intelligent Transportation Systems (ITSC). https://doi.org/10.1109/itsc.2017.8317876.

14. Dey K. C., Rayamajhi A., Chowdhury M., Bhavsar P., Martin J. (2016) Vehicle-to-Vehicle (V2V) and Vehicleto-Infrastructure (V2I) Communication in a Heterogeneous. Wireless Network-Performance Evaluation q. Transportation Research Part C, 68, 168-184. https://doi.org/ 10.1016/j.trc.2016.03.008.

15. Jimenez F., Liang Y., Aparicio F. (2012) Adapting ISA System Warnings to Enhance User Acceptance. Accident Analysis \& Prevention, 48, 37-48. https://doi.org/10. 1016/j.aap.2010.05.017.

16. Burgett A., Carter A., Preziotti G. (2001) An Algorithm for Read-End Collision Avoidance Warning Systems. $17^{\text {th }}$ International Technical Conference on the Enhanced Safety of Vehicles. Amsterdam, 4-7 June 2001.

17. Prestl W., Sauer T., Steinle J., Tschernoster O. (2000) The BMW Active Cruise Control ACC. SAE Technical Paper Series, No 2000-01-0344. https://doi.org/10.4271/ 200001-0344.

18. Green M. (2000) How Long Does it Take to Stop? Methodological Analysis of Driver Perception-Brake Times. Transportation Human Factors, 2 (3), 195-216. https://doi.org/ 10.1207/sthf0203_1.

19. Ahmed M. S., Hoque M. A., Rios-Torres J., Khattak A. J. (2018) A Cooperative Freeway Merge Assistance System Using Connected Vehicles. https://arxiv.org/abs/1805. 00508v1.

Received: 08.10.2019

Accepted: 29.11.2019

Published online: 06.12.2019 